\title{
Nitrogen-fixing rhizobial strains isolated from Desmodium incanum DC in Argentina: Phylogeny, biodiversity and symbiotic ability
}

\author{
María Antonieta Toniutti ${ }^{a}$, Laura Viviana Fornasero ${ }^{a}$, Francisco Javier Albicoro ${ }^{b}$, \\ María Carla Martini ${ }^{\mathrm{b}}$, Walter Draghi ${ }^{\mathrm{b}}$, Florencia Alvarez ${ }^{\mathrm{b}}$, Antonio Lagares ${ }^{\mathrm{b}}$, \\ José Francisco Pensiero ${ }^{\mathrm{a}}$, María Florencia Del Papa ${ }^{\mathrm{b}, *}$ \\ a Facultad de Ciencias Agrarias, Universidad Nacional del Litoral, Santa Fe, Argentina \\ b IBBM-Instituto de Biotecnología y Biología Molecular, CONICET-Departamento de Ciencias Biológicas, Facultad de Ciencias Exactas, Universidad \\ Nacional de La Plata, Calles 47 y 115 (1900), La Plata, Argentina
}

\section{A R T I C L E I N F O}

\section{Article history:}

Received 3 January 2017

Received in revised form 18 April 2017

Accepted 19 April 2017

\section{Keywords:}

Desmodium incanum

Native-legume

Rhizobia

\begin{abstract}
A B S T R A C T
Desmodium spp. are leguminous plants belonging to the tribe Desmodieae of the subfamily Papilionoideae. They are widely distributed in temperated and subtropical regions and are used as forage plants, for biological control, and in traditional folk medicine. The genus includes pioneer species that resist the xerothermic environment and grow in arid, barren sites. Desmodium species that form nitrogenfixing symbiosis with rhizobia play an important role in sustainable agriculture. In Argentina, 23 native species of this genus have been found, including Desmodium incanum. In this study, a total of $64 \mathrm{D}$. incanum-nodulating rhizobia were obtained from root nodules of four Argentinean plant populations. Rhizobia showed different abiotic-stress tolerances and a remarkable genetic diversity using PCR fingerprinting, with more than 30 different amplification profiles. None of the isolates were found at more than one site, thus indicating a high level of rhizobial diversity associated with $D$. incanum in Argentinean soils. In selected isolates, 16S rDNA sequencing and whole-cell extract MALDI TOF analysis revealed the presence of isolates related to Bradyrhizobium elkanii, Bradyrhizobium japonicum, Bradyrhizobium yuanmingense, Bradyrhizobium liaoningense, Bradyrhizobium denitrificans and Rhizobium tropici species. In addition, the nodC gene studied in the selected isolates showed different allelic variants.

Isolates were phenotypically characterized by assaying their growth under different abiotic stresses. Some of the local isolates were remarkably tolerant to high temperatures, extreme $\mathrm{pH}$ and salinity, which are all stressors commonly found in Argentinean soils. One of the isolates showed high tolerance to temperature and extreme $\mathrm{pH}$, and produced higher aerial plant dry weights compared to other inoculated treatments. These results indicated that local isolates could be efficiently used for $D$. incanum inoculation.
\end{abstract} (C) 2017 Elsevier GmbH. All rights reserved.

\section{Introduction}

The genus Desmodium is a large member of the Papilionaceae (Fabaceae) family [21]. It contains about 350 species which are mainly distributed in tropical and subtropical regions of the world, as well as approximately 23 species that are distributed in Argentina [49]. Within the Leguminosae, the tribe Desmodieae (Benth.) Hutch is known for its significant contribution to forage production in the tropics, and includes several species of agronomic concern. These species have the capacity to adapt to low-fertility soils and they tolerate water drought, representing important

\footnotetext{
* Corresponding author. Fax: +54 221422 3409x56.

E-mail address: floppy@biol.unlp.edu.ar (M.F. Del Papa).
}

plant genetic resources for forage production, soil preservation and improvements in marginal smallholder farming systems of subhumid and humid tropical regions [24].

In Argentina, large areas are dominated by grasslands, which constitute a highly diverse forage resource, mostly used as a single feed for livestock [37]. Native leguminous plants are frequently found in these areas where legume-rhizobial symbiosis is responsible for an increase in the nitrogen $(\mathrm{N})$ content of the soil-plant system via the mechanism of biological nitrogen fixation [46].

The introduction of new leguminous species is an approach for maximizing the $\mathrm{N}$-fertility of soils in these areas and increasing the protein content of pastures. In this context, $D$. incanum would be a promising alternative for forage preservation because of its potential for recovering native grassland areas affected by crops. In particular, D. incanum DC inhabits areas with abundant or 
scarce rainfall, and can be found in forest and savannah in floodplains, roadsides and cultivated areas. This legume has the ability to adapt to a wide range of sandy to clay soils and $\mathrm{pH}(4-8)$, as well as having a high rate of survival in low fertility soils [12], although it grows better in slightly alkaline or neutral and fertile soils [20]. In addition, the phytoremediation potential of $D$. incanum in petroleum-contaminated soil was recently demonstrated [28]. The known ability of wild $D$. incanum to tolerate these diverse conditions would make it a promising alternative for feeding animals in north central and northwest regions of Argentina.

Few investigations have focused on the isolation, analysis and symbiotic characterization of rhizobial strains able to associate with Desmodium spp. [9,29]. On the basis of earlier studies in Central and North America, all rhizobial strains isolated from Desmodium spp. have been classified as bradyrhizobia [52]. Similar results were found in temperate and subtropical regions of China, where most isolates from diverse Desmodium species were characterized and identified as Bradyrhizobium spp. However, some isolates from the genera Rhizobium, Sinorhizobium and Mesorhizobium were also reported [22]. Therefore, considering the potential usage of Desmodium spp. as a forage crop $[9,36,48]$, the nature and symbiotic characteristics of rhizobia associated with these legumes has warranted investigation.

However, to date, Desmodium spp. microsymbionts growing in South America, particularly in Argentina, have not been systematically studied. Therefore, the aim of this study was to investigate the biodiversity of rhizobial symbionts associated with $D$. incanum in Argentinean soils and their adaptation to this environment in order to: (1) identify $D$. incanum symbionts in Argentina and their possible relationship with those found in Asia and North America, and (2) determine how these symbionts have adapted to the stress conditions commonly found in Argentinean soils. For this purpose, D. incanum symbionts were sampled in four Argentinean regions in order to analyze their taxonomic and phenotypic diversity. In addition, symbiotic performance with $D$. incanum using natural soil samples was evaluated as a potential target for manufacturing and utilization in forage production.

\section{Materials and methods}

\section{Desmodium incanum study populations}

Root nodules, soil samples and seeds of $D$. incanum populations were collected from four different Argentinean areas. Geolocation data are presented in Table S1 and they were identified under numbers Pensiero 6926, 6935, 7565 and 6897 in the SF Herbarium, Facultad de Ciencias Agrarias, Universidad Nacional del Litoral, Santa Fe, Argentina. The physicochemical characteristics of each sampling area are shown in Table S2. Seeds were collected from 20 to 40 plants to ensure a representative sample and they were stored at $4{ }^{\circ} \mathrm{C}$.

\section{Bacterial cultivation and preservation}

Bacterial strains were routinely cultivated in yeast extract-mannitol (YEM) medium [51] and tryptone yeast (TY) medium [10] at $28^{\circ} \mathrm{C}$. For solid media, $15 \mathrm{~g}$ agar per liter of medium were added. Bacterial isolates were conserved at $-20^{\circ} \mathrm{C}$ in $20 \%$ (v/v) glycerol-TY.

\section{Collection of D. incanum-nodulating rhizobia isolated from} Argentinean soil samples

Soil samples and seeds were collected and investigated for the presence of rhizobia using $D$. incanum as a trap plant. The harvested seeds were surface-sterilized and used to produce trap plants to recover $D$. incanum-nodulating rhizobia from soil samples obtained at the same locations where the seeds had been collected. Experiments were performed in a chamber at $28^{\circ} \mathrm{C}$ with a $16 \mathrm{~h}$-light photoperiod under controlled conditions for two months.

Field- and laboratory-collected nodules were surface-sterilized, as reported by Del Papa et al. [16]. Bacterial isolates were confirmed for their $D$. incanum-nodulation phenotype and conserved as previously stated.

\section{Evaluation of rhizobial sensitivity to abiotic stresses operating in} the soils populated with $\mathrm{D}$. incanum

Each isolate's ability to grow in different $\mathrm{NaCl}$ concentrations, $\mathrm{pH}$ and temperature was tested on solid YEM media under different stress conditions using the following procedure: $10 \mu \mathrm{L}$ of an isolate culture dilution containing ca. $10^{4}$ cells were spotted onto the YEM plates for the various conditions evaluated. For salt and $\mathrm{pH}$ assays, the ability of each isolate to grow on the different plates and under the specific conditions was recorded after 10 days incubation at $28^{\circ} \mathrm{C}$. The isolate's ability to grow at various $\mathrm{NaCl}$ concentrations $(0.5,1.0,2.0$, and $3.0 \% \mathrm{w} / \mathrm{v})$ or on YEM plates containing media at $\mathrm{pH} 4.0,5.0,6.0,7.0,8.0,9.0$, and 10.0 was evaluated. The temperature effect on isolate growth was recorded after 10 days incubation on YEM plates ( $\mathrm{pH} 7.0, \mathrm{NaCl} 0.01 \%$ ) at $28,35,40$, or $45^{\circ} \mathrm{C}$. In all these tests, bacterial growth was estimated on a $0-3$ scale $(0$, lack of growth; 3, full development). Type strains of $R$. hainanense CCBAU57015 ${ }^{\mathrm{T}}$, B. yuanmingense CCBAU $10071^{\mathrm{T}}$, B. elkanii USDA $76^{\mathrm{T}}$, and $B$. liaoningense $U 3622^{\mathrm{T}}$ species [22] were also included. Rhizobial cells grown on YEM ( $\mathrm{pH} 7.0, \mathrm{NaCl} 0.01 \%$ ) and incubated at $28^{\circ} \mathrm{C}$ were used as controls.

\section{Seed disinfection}

D. incanum, Macroptilium lathyroides and Vicia sativa seeds were first manually scarified with sandpaper. Then, these or Phaseolus vulgaris and Glycine max seeds were surface-sterilized as described by Fornasero et al. [19], rinsed with sterile distilled water and kept in water for one hour for swelling. Surface-sterilized seeds were germinated on water-agar plates $(1.0 \% \mathrm{w} / \mathrm{v})$.

\section{Ability of selected rhizobial isolates to support plant growth, plant nodulation and symbiotic efficiency evaluation}

D. incanum seeds were surface-sterilized, as described by Fornasero et al. [19], rinsed with sterile distilled water and kept in water for one hour for swelling. Seeds were then germinated in $1 \%$ $(\mathrm{w} / \mathrm{v})$ water-agar plates and afterwards planted in pots containing sterile vermiculite:perlite $(1: 1)$.

The ability of rhizobial isolates to support plant growth in the absence of fixed nitrogen was evaluated by nodulation tests in sterile support and Jensen mineral solution [26]. Seedlings were planted in plastic pots containing sterile vermiculite:perlite $(1: 1)$, and plants were inoculated with $10 \mathrm{~mL}$ rhizobial suspension containing ca. $10^{8} \mathrm{cfu} \mathrm{mL}^{-1}$ after 15 days. Each strain was evaluated at least in triplicate, with uninoculated and $\mathrm{N}$-fertilized plants being used as controls. The experiments were carried out in a chamber at $28^{\circ} \mathrm{C}$ with a $16 \mathrm{~h}$-light photoperiod. At two months post-inoculation, plants were dried at $60^{\circ} \mathrm{C}$ for aerial and root mass dry-weight estimation. In addition, root nodules were counted, nodules were dried in an oven at $60^{\circ} \mathrm{C}$ to constant weight and the dry weight per plant was determined. For cross nodulation assays, Macroptilium lathyroides, Vicia sativa, Phaseolus vulgaris and Glycine max plants were employed. In order to evaluate the infectivity of isolates, five seedlings were transferred to pots containing sterile vermiculite:perlite (1:1). Seedlings were inoculated with individual strains by adding exponentially growing rhizobial cultures 
$\left(10^{8} \mathrm{cfu} /\right.$ seedling). Uninoculated seedlings were used as negative controls. In all assays, plants were analyzed two months after inoculation.

DNA preparation and PCR set up for strain analysis.

DNA preparation and manipulation were carried out with previously established techniques [41].

\section{BOXA1R PCR genomic-fingerprinting analysis}

The rhizobial isolate collection was genotypically typed by total DNA-amplification fingerprints using either BOXA1R or MBOREP [50] primers, as described by Fornasero et al. [19]. Fingerprint profiles were analyzed using FAMD 1.2 software [43].

\section{Amplification of nodC gene partial sequences}

The nodC gene fragments ( $848 \mathrm{bp}$ ) from $D$. incanum-nodulating isolates were amplified with primers nodCF-nodCI using the cycling conditions described by Laguerre et al. [30].

\section{Amplification of partial 16S rDNA sequences}

DNA fragments (ca. $1440 \mathrm{bp}$ ) containing partial nucleotide sequences of the $16 \mathrm{~S}$ rDNA gene from $D$. incanum-nodulating isolates were amplified with primers $27 \mathrm{f}$ and $1385 \mathrm{r}$, as described by Weidner et al. [55].

\section{DNA sequencing and phylogenetic analysis}

The partial nucleotide sequences of $16 \mathrm{~S}$ rDNA and nodC were obtained by the sequencing service at INTA Castelar (Argentina) and deposited in GenBank under the accession numbers KX857639 to KX857654 and KX857655 to KX857659, respectively. DNA and protein similarity searches were carried out with the BLAST program from the National Center for Biotechnology Information [4]. The 16S rDNA sequence analysis was performed against the EzBiocloud $16 \mathrm{~S}$ rDNA database (which only contains the curated sequences from type strains; http://www.ezbiocloud.net/). Nucleotide sequences were aligned with ClustalW [47]. The MEGA7 software package was used for phylogenetic analyses using the setting indicated in each specific figure. nodC alignments were performed using sequence stretches that covered ca. $680 \mathrm{bp}$ with the homologous positions to nucleotides $460-1140$ in B. elkanii USDA $76^{\mathrm{T}}$ nodC (HQ233221). Alignments of 16S rDNA internal fragments were performed using sequence stretches that covered the homologous positions to nucleotides $180-1350$ in B. elkanii USDA $76^{\mathrm{T}} 16 \mathrm{~S}$ rDNA (U35000).

\section{Matrix-assisted laser desorption/ionization time-of-flight mass spectrometry (MALDI-TOF MS) analysis}

Identification and classification of rhizobia by MALDI-TOF MS was performed using an Ultraflex III MALDI-TOF/TOF mass spectrometer and the MALDI Biotyper 3.1 software (Bruker Daltonics, Bremen, Germany), according to Jia et al. [27]. Firstly, a reference database with Rhizobium and Bradyrhizobium was built, as previously reported by Ferreira et al. [18] and Sánchez-Juanes et al. [42]. Rhizobium strains included in the extended MALDI Biotyper 3.1 library database for MALDI-TOF MS-based species identification are shown in Table S3. Sample preparation was carried out according to the manufacturer's recommendation, either by picking a single colony (direct smear) or using $1 \mu \mathrm{L}$ proteincontaining supernatant (ethanol/formic acid extraction method) from Bradyrhizobium spp. and Rhizobium spp. strains cultured in peptone-salts-yeast extract (PSY) medium supplemented with $0.1 \%$ arabinose or TY medium, respectively. Samples were spotted onto the MALDI target and overlaid with a $1 \mu \mathrm{L}$ saturated solution of $\alpha$-cyano-4-hydroxycinnamic acid in an organic solution (50\% acetonitrile, $2.5 \%$ trifluoroacetic acid). Spectra were recorded by Flex Control 3.3 software (Bruker Daltonics) in a linear positive mode at an accelerated voltage of $19 \mathrm{KV}$ in the range from 2 to $20 \mathrm{KDa}$. The laser intensity was chosen in order to obtain spectra with maximum absolute peak intensities, ranging from approximately $5 \times 10^{3}$ to $10^{4}$ arbitrary units. External calibration was performed with the Bruker bacterial test standard (Bruker Daltonics). MALDI-TOF MS identifications were classified using the score values described in Ferreira et al. [18]: $\geq 2$ species identification; between 1.7 and 1.9 genus identification; $<1.7$ no identification.

\section{Statistical calculations and analyses}

Statistical calculations were performed with the software package InfoStat [14]. Analysis of variance (ANOVA) and Tukey's test were performed on the plant and root dry weights and the total $\mathrm{N}$ per plant. For the principal components analysis (PCA) of the stresstolerance phenotypes, the XLSTAT software package was used.

\section{Results}

Isolation of rhizobia from $\mathrm{D}$. incanum root nodules and analysis of microbial diversity

In order to study the diversity of native rhizobial populations able to nodulate $D$. incanum, different regions from Argentina were sampled and investigated for the presence of nodulated plants naturally present at the different sampling sites (Table S1). In addition, a trap-plant assay was performed in order to obtain $D$. incanumnodulating rhizobia in greenhouse experiments. In this regard, a rhizobial collection was assembled comprising a total of 64 isolates, including those recovered from different trap plants grown in pots (62 isolates), as well as isolates from field-nodulated plants (2 isolates).

The diversity of the 64 rhizobial germplasms associated with $D$. incanum was assessed by BOXA1R and MBOREP PCR-fingerprinting (Fig. S1). A UPGMA dendrogram analysis based on the Dice similarity index extracted from the electrophoretic mobility of amplified DNA fragments (Fig. S2) revealed notable genetic diversity among $D$. incanum-nodulating rhizobia in Argentinean soils (strain richness index of 0.32) [33]. Bacterial isolates recovered from populations 5,8 , and 9 were highly diverse (strain richness index of 0.55 ; 0.62 and 0.41 , respectively) [33]. By contrast, isolates recovered from population 10 (Corrientes Province) formed a single group with approximately $>90 \%$ similarity among the bacterial isolates. The genetic heterogeneity of the rhizobial collection of populations 5, 8, and 9 was detected using both the MBOREP PCR and BOXA1R approaches. Taken together, these results showed that $D$. incanum-nodulating rhizobia showed different levels of similarity between the studied populations.

\section{Phenotypic diversity of rhizobial isolates}

In order to explore the phenotypic diversity of the strain collection, the 64 rhizobial isolates were evaluated for their capacity to grow on YEM solid media under different stress conditions that commonly occur in local agricultural soils (e.g. extreme $\mathrm{pH}$, high temperature and high salinity; Table S4). Thus, $98 \%$ of isolates behaved as slow-growing rhizobia on YEM medium at $28^{\circ} \mathrm{C}$.

The results showed that although $97 \%$ of the isolates were unable to grow at $3 \%[\mathrm{w} / \mathrm{v}] \mathrm{NaCl}, 44 \%$ of the isolates were able to grow in the presence of a low amount of salt $(0.5 \%[\mathrm{w} / \mathrm{v}] \mathrm{NaCl})$. Only 6\% of the isolates (P5 97, P5 94, P10 115 and P10 117) were able to grow well on YEM medium supplemented with $2 \%(\mathrm{w} / \mathrm{v})$ $\mathrm{NaCl}$ (score 2, in a 0-3 scale) and showed a broad $\mathrm{pH}$ tolerance. 
Table 1

Growth of rhizobia that nodulate Desmodium incanum evaluated under different abiotic stress conditions on YEM agar medium.

\begin{tabular}{|c|c|c|c|c|c|c|c|c|c|c|c|c|c|c|c|c|c|}
\hline \multirow[t]{2}{*}{ Population } & \multirow[t]{2}{*}{ ID } & \multicolumn{4}{|c|}{$\begin{array}{l}\text { Growth at the indicated } \\
\text { temperature }\left({ }^{\circ} \mathrm{C}\right)\end{array}$} & \multicolumn{6}{|c|}{$\begin{array}{l}\text { Growth at the } \\
\text { indicated } \mathrm{pH}\end{array}$} & \multicolumn{5}{|c|}{$\begin{array}{l}\text { Growth at the } \\
\text { indicated } \mathrm{NaCl}(\% \mathrm{w} / \mathrm{v}) \\
\text { concentrations }\end{array}$} & \multirow[t]{2}{*}{ BOXA1R Type } \\
\hline & & $28^{\circ}$ & $35^{\circ}$ & $40^{\circ}$ & $45^{\circ}$ & 4 & 5 & 6.8 & 8 & 9 & 10 & 0.01 & 0.5 & 1 & 2 & 3 & \\
\hline \multirow[t]{4}{*}{ P5 } & 97 & 3 & 2 & 1 & 0 & 0 & 2 & 3 & 3 & 2 & 2 & 3 & 3 & 2 & 2 & 0 & A \\
\hline & 501 & 3 & 0 & 0 & 0 & 0 & 3 & 3 & 3 & 3 & 3 & 3 & 1 & 0 & 0 & 0 & B \\
\hline & 505 & 3 & 3 & 1 & 0 & 0 & 3 & 3 & 3 & 0 & 0 & 3 & 0 & 0 & 0 & 0 & $C$ \\
\hline & 514 & 3 & 3 & 2 & 0 & 0 & 2 & 3 & 3 & 1 & 0 & 3 & 0 & 0 & 0 & 0 & D \\
\hline \multirow[t]{4}{*}{ P8 } & 802 & 3 & 3 & 0 & 0 & 0 & 3 & 3 & 2 & 0 & 0 & 3 & 0 & 0 & 0 & 0 & $\mathrm{E}$ \\
\hline & 810 & 3 & 3 & 1 & 0 & 1 & 2 & 3 & 3 & 1 & 0 & 3 & 2 & 1 & 0 & 0 & $\mathrm{E}$ \\
\hline & 823 & 3 & 3 & 0 & 0 & 0 & 3 & 3 & 2 & 0 & 0 & 3 & 0 & 0 & 0 & 0 & $\mathrm{~F}$ \\
\hline & 828 & 3 & 3 & 0 & 0 & 0 & 2 & 3 & 0 & 0 & 0 & 3 & 0 & 0 & 0 & 0 & G \\
\hline \multirow[t]{4}{*}{ P9 } & 118 & 3 & 3 & 2 & 0 & 3 & 3 & 3 & 1 & 1 & 0 & 3 & 0 & 0 & 0 & 0 & $\mathrm{H}$ \\
\hline & 904 & 3 & 3 & 2 & 0 & 3 & 3 & 3 & 1 & 1 & 0 & 3 & 0 & 0 & 0 & 0 & $\mathrm{H}$ \\
\hline & 907 & 3 & 3 & 1 & 0 & 0 & 3 & 3 & 0 & 0 & 0 & 3 & 0 & 0 & 0 & 0 & I \\
\hline & 915 & 3 & 3 & 2 & 0 & 0 & 3 & 3 & 3 & 0 & 0 & 3 & 0 & 0 & 0 & 0 & $\mathrm{~J}$ \\
\hline \multirow[t]{4}{*}{ P10 } & 85 & 3 & 3 & 0 & 0 & 1 & 3 & 3 & 2 & 1 & 0 & 3 & 2 & 1 & 0 & 0 & $\mathrm{~K}$ \\
\hline & 102 & 3 & 3 & 0 & 0 & 0 & 3 & 3 & 2 & 2 & 0 & 3 & 1 & 0 & 0 & 0 & $\mathrm{~K}$ \\
\hline & 117 & 3 & 2 & 1 & 0 & 3 & 3 & 3 & 3 & 3 & 1 & 3 & 3 & 3 & 2 & 0 & $\mathrm{~L}$ \\
\hline & 130 & 3 & 2 & 2 & 0 & 3 & 3 & 3 & 3 & 2 & 1 & 3 & 1 & 0 & 0 & 0 & M \\
\hline \multirow[t]{4}{*}{$S$} & 1 & 3 & 2 & 0 & 0 & 0 & 2 & 3 & 3 & 0 & 0 & 3 & 0 & 0 & 0 & 0 & - \\
\hline & 2 & 3 & 3 & 0 & 0 & 0 & 2 & 3 & 3 & 1 & 0 & 3 & 2 & 0 & 0 & 0 & - \\
\hline & 3 & 3 & 3 & 0 & 0 & 0 & 2 & 3 & 1 & 0 & 0 & 3 & 1 & 0 & 0 & 0 & - \\
\hline & 4 & 3 & 2 & 0 & 0 & 1 & 3 & 3 & 3 & 2 & 2 & 3 & 3 & 2 & 1 & 0 & - \\
\hline
\end{tabular}

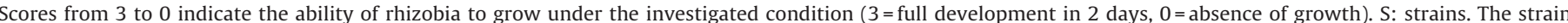

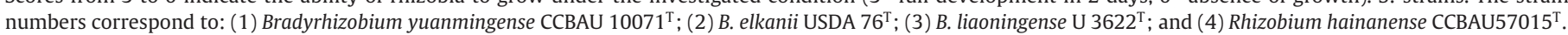

Most selected isolates grew significantly over a wide range of $\mathrm{pH}$, whereas isolates P5 97 and P5 501 grew in pH ranging from 5 to 10, and isolates P10 117 and P10 130 grew within the range of 4-10. Some rhizobial isolates (P5 97, P5 505, P5 514, P8 810, P9 118, P9 904, P9 915, P10 117, P10 130 among others) exhibited the combined ability to grow well at $\mathrm{pH} 8$ and $40^{\circ} \mathrm{C}$, which is a temperature commonly found in the geographic region populated by $D$. incanum in Argentina.

Overall stress conditions acting on the physiology of the different isolates were determined by multivariate analysis. PCA (Pearson-n; XLSTAT software package) was performed with reference to the numerical-tolerance ranking of each isolate for each stress (variables). Isolate distribution in the PC1-PC2 space served to group isolates into regions of clear dominance with respect to each of the investigated stress tolerance phenotypes, as follows: lower right, tolerance to high $\mathrm{pH}$; upper right, tolerance to low $\mathrm{pH}$ and high temperature; right center, salt tolerance (Fig. 1). These two components together represented approximately $50 \%$ of the observed phenotypic variation.

Phenotypical results indicated that the rhizobial collection comprised isolates with different levels of abiotic stress tolerance, and that some isolates tolerated more than one stress (Table S4). Therefore, isolate selection was based on broader selective criteria in order to choose bacterial strains with pronounced tolerance to abiotic stresses that would benefit the end user by the successful establishment of the strain showing the desired phenotypes. Consequently, 16 native rhizobial isolates were selected as candidates for further evaluation of their taxonomy and symbiotic properties (Table 1).

\section{Phylogeny of chromosomal and symbiotic markers from selected rhizobial isolates}

\section{$16 S$ rDNA}

In order to infer the taxonomic position of the isolates obtained, an internal fragment of the 16S rRNA gene was amplified by PCR, and its nucleotide sequences were compared with the homologous amplicons from rhizobia type strains (Table S5). Fig. 2 shows the phylogenetic analysis of the 16S rRNA gene, includ- ing recently described Bradyrhizobium and Rhizobium species. The results showed the placement of 15 selected isolates within the bradyrhizobial clade (i.e. closely related to $B$. yuanmingense, $B$. guangxiense, B. denitrificans, B. elkanii, and B. kavangense among others), whereas isolate P10 117 was included within a rhizobial clade close to $R$. tropici, $R$. hainanense, and $R$. multihospitium.

Among the Bradyrhizobium spp. isolates, strains P9 118, P5 505, P9 904, P10 130, P9 907, P5 514 P8 823, P8 828 and P9 915 were located in group I, and strains P10 85, P10 102, P5 501, P8 802, P8 810 and P5 97 in group II, according to the phylogenetic division of the genus Bradyrhizobium proposed by Menna et al. [34]. Gu et al. [22] and Granada et al. [20] previously reported that most Desmodium species microsymbionts belonged to Bradyrhizobium species closely related to B. elkanii, B. japonicum, and B. yuanmingense. The results in the current study demonstrated that the $D$. incanum population present in Argentina could be nodulated by either bradyrhizobia or rhizobia strains (Fig. 2).

$\operatorname{nodC}$

The nodC gene encodes for $N$-acetylglucosaminyltransferase, the enzyme responsible for the first step in rhizobial Nod factor assembly [35]. Based on the results indicating that diverse species of rhizobia were able to nodulate $D$. incanum, nodC phylogeny was investigated in some of the 16 native rhizobial isolates selected for their phenotypic and/or symbiotic properties. These sequences would help to assess similar or different nodC alleles in geographically different $D$. incanum-nodulating isolates, and to determine whether there really was some kind of preference of the host plant in relation to the nodC sequence. BLASTn sequence analysis showed that the nodC genes from P5 514, P8 810, P9 118, P9 915 and P10 85 isolates were highly similar to the B. elkanii nodC gene. However, Fig. 3 shows that nodC from strains P9 915 and P10 85 clustered within a nodC clade that included $B$. tropiciagri isolated from root nodules of Neonotonia wightii, a nitrogen-fixing symbiont of soybean [15]. By contrast, the nodC fragments from P5 514 and P9 118 were highly similar over the amplified fragment and did not cluster with any of the reported bradyrhizobial nodC variants. nodC from P8 810 clustered with $B$. neotropicale. Unfortunately, none of the primer pairs reported by Laguerre et al. [30] allowed the amplifica- 

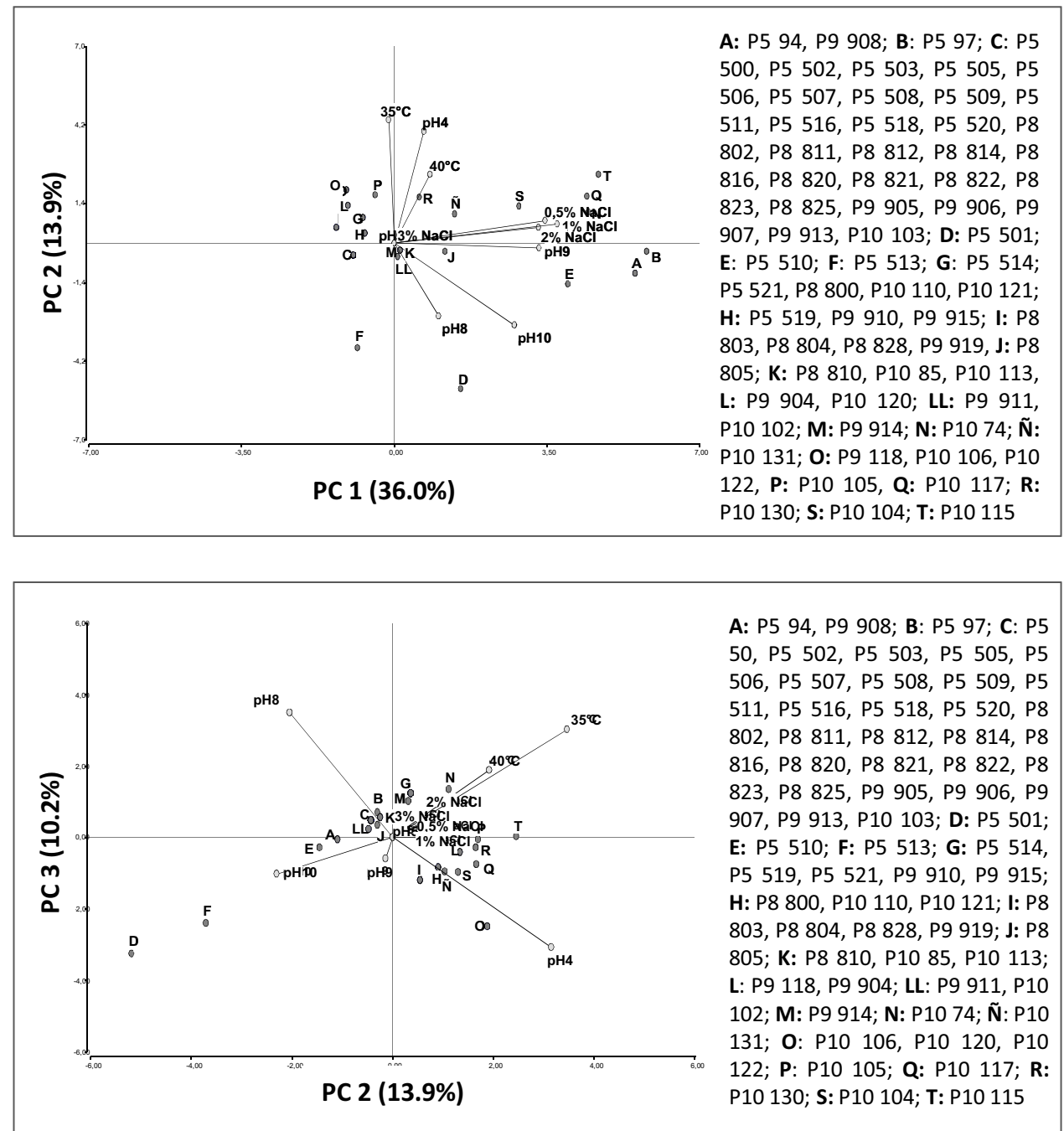

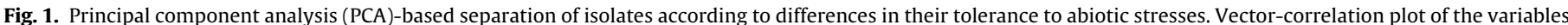

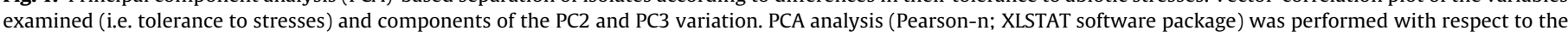

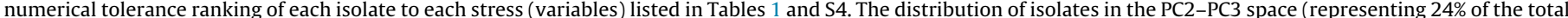

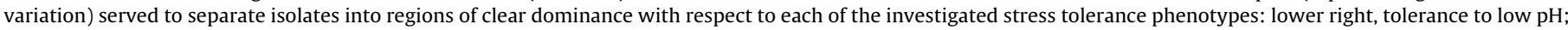
upper right, tolerance to high temperature; upper right, salt tolerance.

tion of the nodC fragment from the local Rhizobium sp. P10 117 and Bradyrhizobium sp. P10 130 strains, suggesting that these isolates carried nodC allelic variants different from those in the rhizobial and bradyrhizobial symbionts characterized here. These results showed that $D$. incanum was nodulated by different rhizobia that may code phylogenetically different nodC genes.

\section{Identification of rhizobial strains by MALDI-TOF MS analysis}

It is widely known that $16 \mathrm{~S}$ rDNA has a limited resolution for solving taxonomic positions at the species level [7]. In order to improve taxonomic allocation by sequencing the 16S rRNA gene, strain identification was applied using MALDI-TOF MS as a complementary method to rapidly identify bacterial isolates and further discriminate the species of the selected rhizobial isolates [59]. Fig. S3 shows the mass spectra of the selected isolates of each population. The P5 505, P5 514, P8 828, P9 118, P9 904, P9 907 and P10 130 mass spectra were similar to the $B$. yuanmingense spectrum, whereas those for isolates P5 97, P5 501, P8 802, P8 810, P10 85 and P10 102 were similar to the B. elkanii spectrum. Finally, the P8 823 mass spectrum corresponded to that of B. japonicum. Although P9 915, in particular, could not be identified with a high score, it had the typical Bradyrhizobium spp. spectrum and a low identification score with B. denitrificans (Fig. 2, Table 2).

\section{Symbiotic properties of the isolates}

Some D. incanum seeds collected from Argentina populations did not germinate well. Due to the low germination percentage and the lack of a commercial source for $D$. incanum seeds, $D$. incanum nodulation tests could only be performed with selected isolates. First, a preliminary experiment was performed in a growth chamber in order to compare the symbiotic efficiency of the 16 selected native rhizobial isolates (shown in Table 1) on D. incanum plants. The reference strain $R$. hainanense CCBAU57015 ${ }^{\mathrm{T}}$ was used as a positive control, as it is known to induce nodules in Desmodium species [22].

Differences among the analyzed strains were revealed in $\mathrm{N}$-free mineral solution. In fact, six Bradyrhizobium strains isolated from different sites (P5 514, P8 810, P9 118, P9 915, P10 85 and P10 130 ) showed statistically significant differences in their nodulation pattern (data not shown) and shoot dry biomass production (Fig. 4). Nodule dry weight and shoot dry weight correlation in this host was 


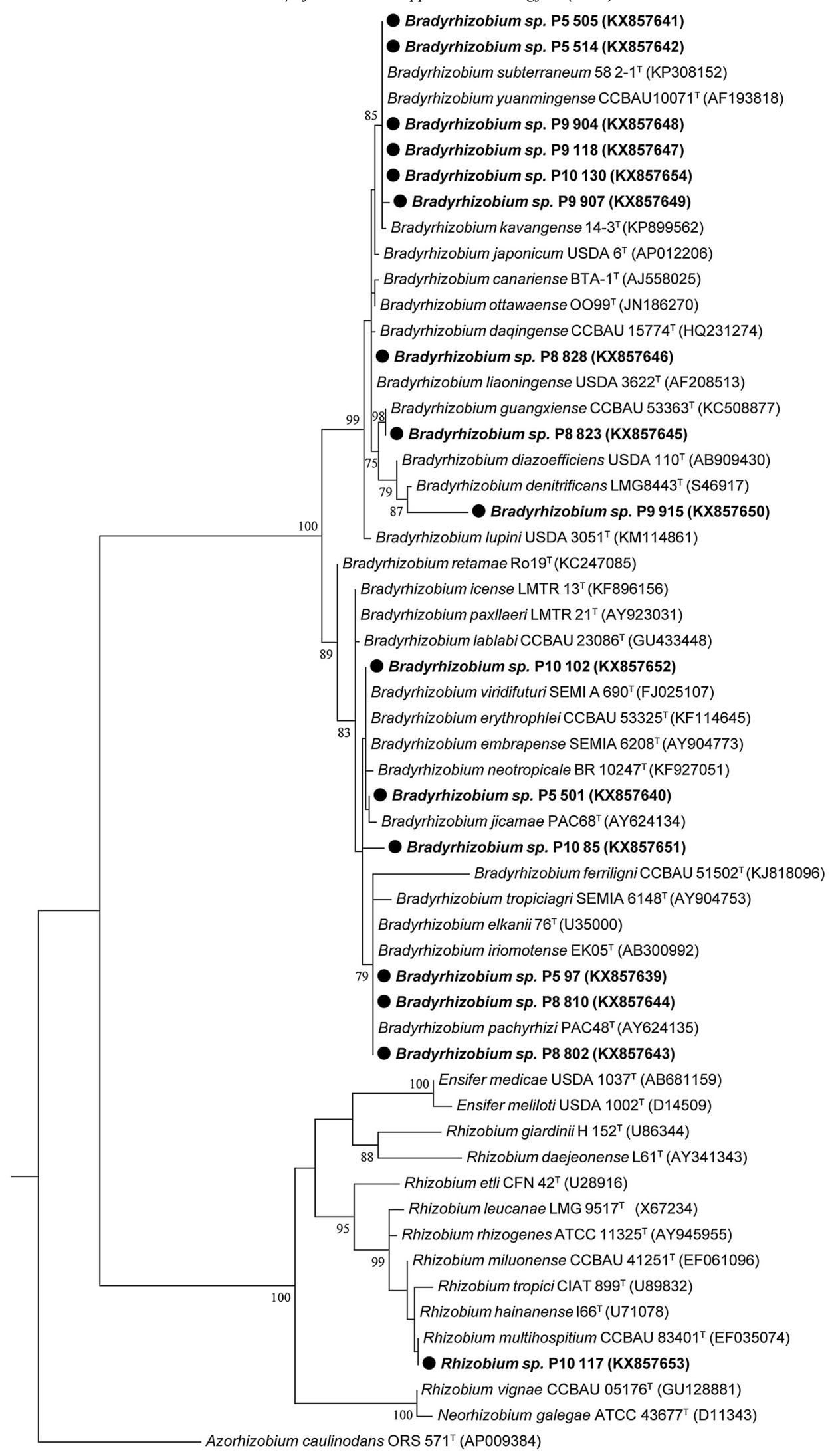

Fig. 2. Phylogenetic analysis based on $16 \mathrm{~S}$ rDNA sequences from the isolates recovered from $D$. incanum plants collected in Argentina. The evolutionary history was inferred by using the maximum likelihood method based on the Tamura 3-parameter model, which showed the lowest BIC scores (Bayesian Information Criterion) considered as the best for describing the substitution pattern. The tree with the highest log likelihood $(-3524.4965)$ is shown. The percentage of trees in which the associated taxa clustered together is shown next to the branches. Initial tree(s) for the heuristic search were obtained automatically by applying neighbor-joining and BioNJ algorithms to a matrix of pairwise distances estimated using the maximum composite likelihood (MCL) approach, and then selecting the topology with the highest log likelihood value. A discrete gamma distribution was used to model evolutionary rate differences between sites ( 5 categories $(+G$, parameter $=0.2313)$ ). The rate variation model allowed for some sites to be evolutionarily invariable ([+I], 48.2369\% sites). The analysis involved 56 nucleotide sequences. All positions containing gaps and missing data were eliminated. Evolutionary analyses were conducted in MEGA7 [28]. The DNA sequences used were obtained from GenBank under the accession numbers indicated after the name of each rhizobium. Superscript T indicates that strains are type strains. Solid black circles indicate the isolates characterized in this study. 


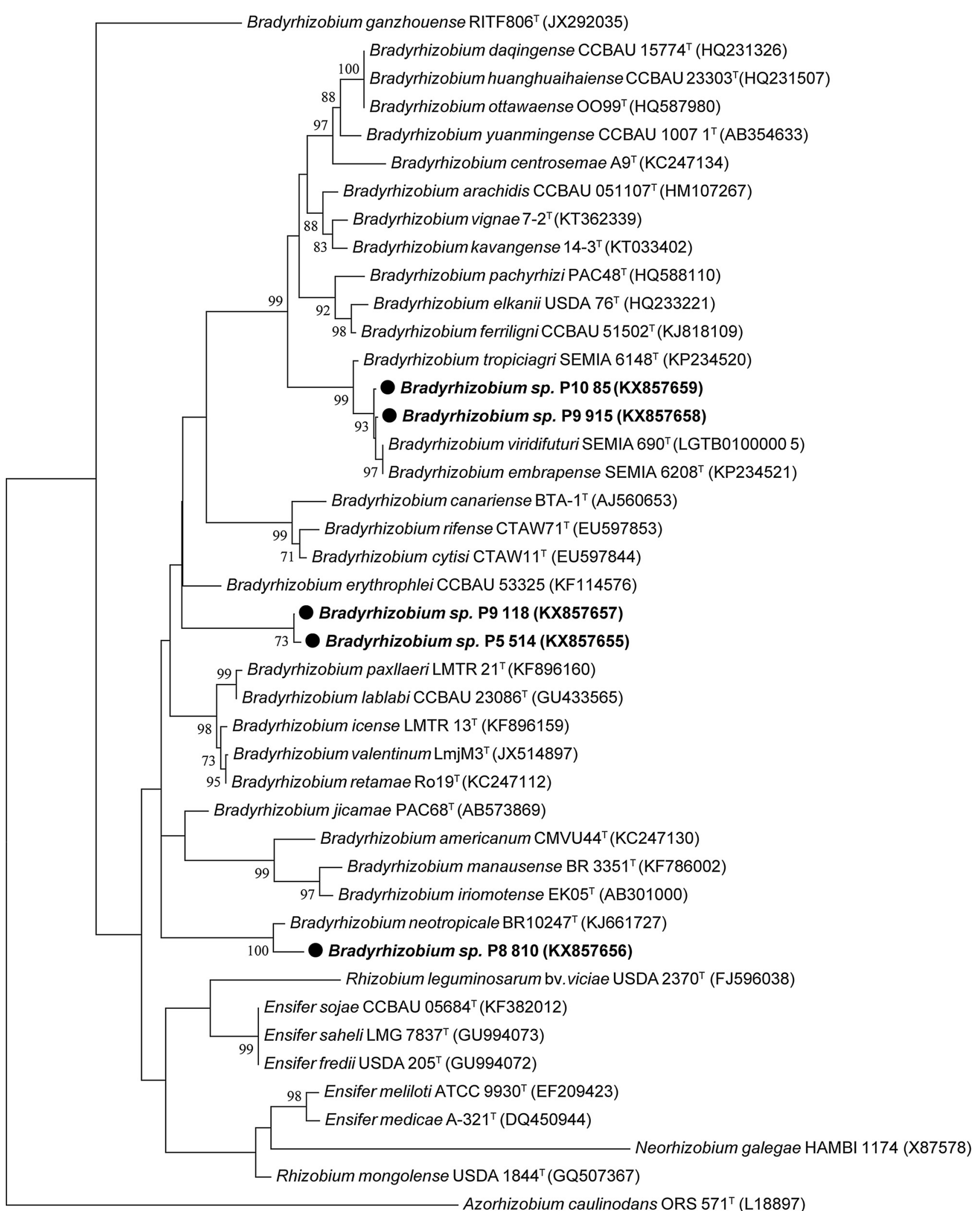

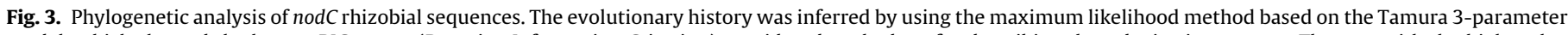

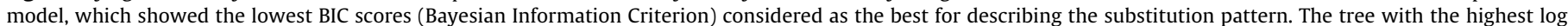

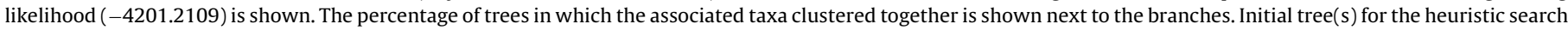

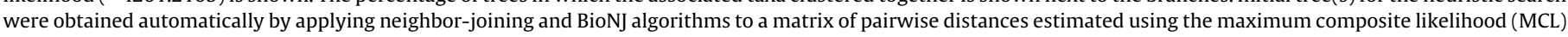

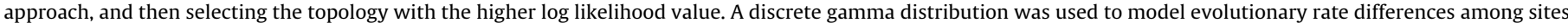

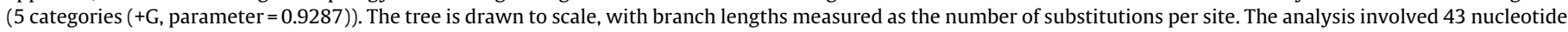

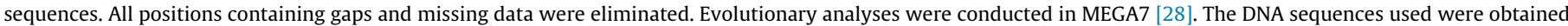

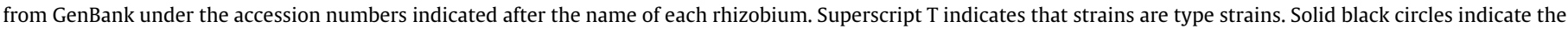
isolates characterized in this study. 
Table 2

MALDI BioTyper identification results for selected $D$. incanum-nodulating isolates.

\begin{tabular}{|c|c|c|}
\hline ID & Organism (best match) & Score $^{\mathrm{a}}$ \\
\hline \multicolumn{3}{|c|}{ Population 5} \\
\hline P5 97 & B. elkanii USDA $76^{\mathrm{T}}$ & 2.266 \\
\hline P5 501 & B. elkanii USDA $76^{\mathrm{T}}$ & 2.088 \\
\hline P5 505 & B. yuanmingense CCBAU0071 ${ }^{\mathrm{T}}$ & 2.350 \\
\hline P5 514 & B. yuanmingense CCBAU $0071^{\mathrm{T}}$ & 2.342 \\
\hline \multicolumn{3}{|c|}{ Population 8} \\
\hline P8 802 & B. elkanii USDA $76^{\mathrm{T}}$ & 2.254 \\
\hline P8 810 & B. elkanii USDA $76^{\mathrm{T}}$ & 2.363 \\
\hline P8 823 & B. japonicum USDA $6^{\mathrm{T}}$ & 2.276 \\
\hline P8 828 & B. yuanmingense CCBAU0071 ${ }^{\mathrm{T}}$ & 2.238 \\
\hline \multicolumn{3}{|c|}{ Population 9} \\
\hline P9 118 & B. yuanmingense CCBAU0071 ${ }^{\mathrm{T}}$ & 2.221 \\
\hline P9 904 & B. yuanmingense CCBAU0071 ${ }^{\mathrm{T}}$ & 2.345 \\
\hline P9 907 & B. yuanmingense CCBAU0071 ${ }^{\mathrm{T}}$ & 2.213 \\
\hline P9 915 & B. denitrificans DSM $1113^{\mathrm{T}(\#)}$ & $1.582(\#)$ \\
\hline \multicolumn{3}{|c|}{ Population 10} \\
\hline P10 85 & B. elkanii USDA $76^{\mathrm{T}}$ & 2.164 \\
\hline P10 102 & B. elkanii USDA $76^{\mathrm{T}}$ & 2.070 \\
\hline P10 117 & Rhizobium tropici CIAT $899^{\mathrm{T}}$ & 2.150 \\
\hline P10 130 & B. yuanmingense CCBAU0071 ${ }^{\mathrm{T}}$ & 2.252 \\
\hline
\end{tabular}

a Score value $>2$ indicates species identification; $1.7<$ score value $<2$ indicates genus identification; score value $<1.7$ indicates no identification (\#) [17].

observed in studies performed in pots with vermiculite and $\mathrm{N}$-free Jensen solution (Fig. S4).

These six bradyrhizobial isolates were checked for cross nodulation in Macroptilium lathyroides, Vicia sativa, Phaseolus vulgaris and Glycine max plants in order to investigate their symbiotic properties. All tested rhizobia failed to nodulate Vicia sativa, which is a restrictive host [5]. In contrast, isolates P8 810, P9 118 and P10 85 nodulated Phaseolus vulgaris, but only P9 118 was capable of significantly increasing the plant shoot dry weights compared with the uninoculated Phaseolus vulgaris treatment. However, isolates P8 810 and P10 85 produced effective nodulation with Macroptilium lathyroides, which is a non-selective host nodulated by rhizobia from different alpha- and betaproteobacterial genera $[17,23,32]$. In addition, none of the six isolates produced nodules in soybean (Glycine max) under the specified experimental conditions, although diverse Bradyrhizobium [13,6,8,25,44,45,53,54,57,58], Rhizobium [3] and Ensifer $[6,31,39,58]$ genera have been reported as Glycine max symbionts.

\section{Discussion}

The study of $D$. incanum-nodulating rhizobia biodiversity is not only important for their role as microsymbionts of legumes with forage potential, but also for their potential as a biotic factor for the establishment of Desmodium species in Argentinean soils. $D$. incanum was found in different soil types and locations from where specimens were collected, which represented the diversity of the phytogeographic districts. In this study, the 64 native strains associated with $D$. incanum showed phenotypic heterogeneity and genetic diversity, despite their site of origin. Many isolates were tolerant to abiotic stresses, such as high temperature and salinity, while a few were also able to grow at a pH as high as 10 in agar-containing solid medium. From an applied point of view, the temperature tolerance shown by some of the isolates could constitute a positive feature that would likely favor rhizobial survival both on the surface of inoculated seeds and in soils. In addition, the genotypic characterization by BOXA1R and MBOREP fingerprinting allowed a high level of genetic diversity to be demonstrated among rhizobial isolates.
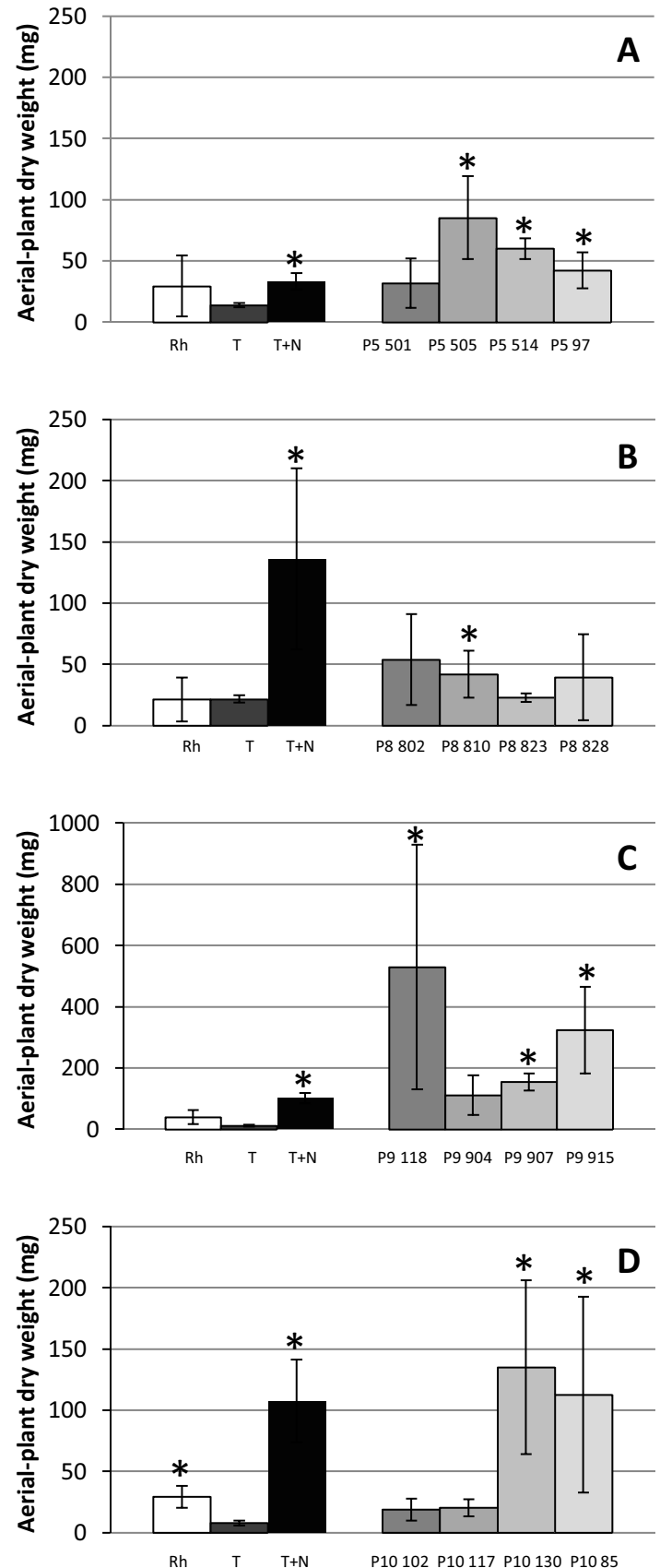

Fig. 4. Symbiotic performance of rhizobial strains. Seeds were recovered from $D$. incanum: (A) Population 5; (B) Population 8; (C) Population 9; (D) Population 10. Uninoculated plants without $\mathrm{N}$ addition $(\mathrm{T}), \mathrm{N}$-fertilized plants $(\mathrm{T}+\mathrm{N}), R$. hainanense CCBAU57015 ${ }^{\mathrm{T}}(\mathrm{Rh})$ and selected rhizobial treatments were included in the experiment. Plants were harvested 60 days after inoculation for dry-weight analyses. Mean \pm SD values of the plant dry weights are shown. Asterisks indicate that the means for the samples are different $(P=0.05)$ from those of uninoculated plants (T).

Regardless of the potential displayed by Desmodium spp. as a forage alternative $[9,36,48]$, little work has been focused on the rhizobial symbionts associated with these particular legumes. Parker's pioneering studies [38] reported the isolation of bacteria from root nodules of $D$. glutinosum, a common herbaceous legume in eastern North America, and indicated that they harbored genotypes similar to B. japonicum. However, these bacteria were closely related to B. elkanii both in terms of the alleles of symbiotic genes and behavior outside the plant. Later, Gu et al. [22] made progress 
in the characterization of rhizobia nodules recovered from nine native Desmodium species growing in temperate and subtropical regions of China. These authors found that more than $70 \%$ of the isolates were identified as slow-growing Bradyrhizobium, which were highly related to B. elkanii, B. japonicum and B. yuanmingense, although they also found some strains associated with Rhizobium, Sinorhizobium and Mesorhizobium. Subsequently, Granada et al. [20] studied the genetic diversity of $D$. incanum-nodulating isolates collected in Brazil. Recently, Xu et al. [56] analyzed 34 strains of rhizobia obtained from the root nodules of four wild Desmodium species found in China, and reported the presence of Rhizobium, Pararhizobium, Mesorhizobium and Bradyrhizobium isolates with a high level of diversity. In this current study, the phylogenetic analysis of $D$. incanum rhizobia symbionts revealed the majority were Bradyrhizobium and isolates clustered with previously characterized Desmodium-nodulating rhizobia according to data available from other countries. The selected $D$. incanum-nodulating isolates mainly belonged to the genus Bradyrhizobium ( $\geq 85 \%$ similarity in the 16S rRNA gene) and were closely related to B. elkanii, $B$. japonicum and B. yuanmingense (Fig. 2). Only one isolate (P10 117) belonged to the genus Rhizobium, with $R$. tropici, $R$. rhizogenes, $R$. hainanense, $R$. multihospitium and $R$. lusitanum as the closest related species (Fig. 2). Misidentification at the species level was observed in some cases in MALDI-TOF analysis. Consequently, the expansion of the data base with the inclusion of other bradyrhizobia that could be more closely related to the studied isolates would certainly improve the sample scores. Therefore, further research involving a polyphasic approach should be conducted in order to shed light on the identification of these strains.

The current findings, together with previous results, indicated that $D$. incanum exhibited a degree of symbiotic promiscuity, since it was nodulated by rhizobia from different genera/species. Such a complex picture prompted us to characterize the type of nod variants (i.e. nodC) present in selected Argentinean isolates and to investigate the phylogenetic relationships with nodC homologs from other rhizobia. Rogel et al. [40] found that the phylogenies of rhizobia nod genes correlated with species of legume guests. Unfortunately, it was not possible to amplify the nodC allele of local isolates Rhizobium sp. P10 117 and Bradyrhizobium sp. P10 130, which suggested the existence of an additional nodC variant associated with $D$. incanum symbionts. The BLASTn analysis of the nodC fragments sequenced in this study showed a high sequence similarity with B. elkanii nodC genes (81-95\% identity) (Table S6), while the nodC sequences of isolates analyzed were members of several clades that included various Bradyrhizobium nodC sequences (Fig. 3). In contrast, Xu et al. [56] analyzed four Desmodium spp. isolates and showed $100 \%$ sequence similarity with nodC genes of Ensifer strains isolated from Leucaena trees in China, whereas other nodC sequences were related to Bradyrhizobium sequences. Altogether, these observations showed that the chromosomal and plasmid phylogenies did not always coincide and that there might be some kind of geographical preference of the host plant in relation to the $\operatorname{nod} C$ sequence. In this sense, Aguilar et al. [1] reported polymorphism in the nodC gene among $R$. etli strains with different nodC alleles in American strains that correlated with the centers of bean genetic diversification. In addition, testing for preferential $D$. incanum nodulation by geographically related rhizobia lineages could provide information concerning possible coevolution in the centers of host genetic diversification. In order to achieve a deep understanding of the early signs of the symbiotic relationship between rhizobia and Desmodium spp., future efforts will be needed in order to undertake nodC gene sequencing from more isolates and other groups of nod genes, in addition to the structural elucidation of the corresponding Nod factors. The underlying question thus is whether or not $D$. incanum symbionts produce the same family of Nod signal molecules or, alternatively, whether all these rhizobia produce a diverse-albeit symbiotically active-set of nodulation factors.

Several isolates were able to support plant growth in the absence of a source of fixed nitrogen and some of them produced higher plant dry weights compared to those of the $\mathrm{N}$-fertilized plants (Fig. 4). The symbiotic performance of native bacteria seems to be related to specific features of each isolate and not to their overall genetic composition, since isolates showing different symbiotic properties were grouped in the same cluster of the 16S rDNA dendrogram (e.g. Bradyrhizobium sp. P10 130 and Bradyrhizobium sp. P5 505, Bradyrhizobium sp. P9 118 and Bradyrhizobium sp. P9 904). In addition, the analysis of root weight in vermiculite allowed the detection of a root-growth-promoting effect of rhizobia P10 130. Although it is not known which mechanisms operate in the promotion of root growth, the inoculated strain could have most likely produced one or more phytohormones, or have used phosphate solubilisation, as has already been observed in other bradyrhizobial strains $[2,11]$.

Taken together, the results obtained in this study showed the characteristics of $D$. incanum-nodulating rhizobia genotypic diversity and the phylogenetic position of the symbionts obtained from Argentinean soils. The available evidence allowed the best candidate for inoculation to be selected based on broader selective criteria. However, the remarkable temperature and broad $\mathrm{pH}$ tolerance of B. yuanmingense P10 130, together with its symbiotic performance in $\mathrm{N}$-free plant medium, make this isolate a suitable candidate as a $D$. incanum rhizobial inoculant that will require more extensive basic and field evaluations.

\section{Acknowledgements}

This work was supported by the National Scientific and Technical Research Council of Argentina (Consejo Nacional de Investigaciones Científicas y Técnicas-CONICET, Argentina) and the Ministry of Science, Technology and Productive Innovation (Ministerio de Ciencia Tecnolología e Innovación Productiva-MinCyT, Argentina) [Grant numbers PIP 2015-0700, PICT 2012-102 and PICT 2012-1719]. MCM and FJA were supported by fellowships from CONICET, whereas AL, JP and MFDP are researchers at CONICET. The authors are grateful to Ulises Mancinni for excellent computing assistance and Paula Giménez and Silvana Tongiani for their excellent technical assistance.

\section{Appendix A. Supplementary data}

Supplementary data associated with this article can be found, in the online version, at http://dx.doi.org/10.1016/j.syapm.2017.04. 004.

\section{References}

[1] Aguilar, O.M., Riva, O., Peltzer, E. (2004) Analysis of Rhizobium etli and of its symbiosis with wild Phaseolus vulgaris supports coevolution in centers of host diversification. Proc. Natl. Acad. Sci. U. S. A. 101 (37), 13548-13553.

[2] Ahemad, M., Kibret, M. (2014) Mechanisms and applications of plant growth promoting rhizobacteria: current perspective. J. King Saud Univ. 26 (1), 1-20.

[3] Alam, F., Bhuiyan, M.A.H., Alam, S.S., Waghmode, T.R., Kim, P.J., Lee, Y.B. (2015) Effect of Rhizobium sp. BARIRGm901 inoculation on nodulation, nitrogen fixation and yield of soybean (Glycine max) genotypes in gray terrace soil. Biosci. Biotechnol. Biochem. 79 (10), 1660-1668.

[4] Altschul, S.F., Madden, T.L., Schäffer, A.A., Zhang, J., Zhang, Z., Miller, W., Lipman, D.J. (1997) Gapped BLAST and PSI-BLAST: a new generation of protein database search programs. Nucleic Acids Res. 25 (17), 3389-3402.

[5] Álvarez-Martínez, E.R., Valverde, Á., Ramírez-Bahena, M.H., García-Fraile, P. Tejedor, C., Mateos, P.F., Santillana, N., Zúñiga, D., Peix, A., Velázquez, E. (2009) The analysis of core and symbiotic genes of rhizobia nodulating Vicia from different continents reveals their common phylogenetic origin and suggests the distribution of Rhizobium leguminosarum strains together with Vicia seeds. Arch. Microbiol. 191 (8), 659-668. 
[6] Appunu, C., Sasirekha, N., Prabavathy, V.R., Nair, S. (2009) A significant proportion of indigenous rhizobia from India associated with soybean (Glycine max L.) distinctly belong to Bradyrhizobium and Ensifer genera. Biol. Fertil. Soils 46 (1), 57-63.

[7] Azevedo, H., Lopes, F.M., Silla, P.R., Hungria, M. (2015) A database for the taxonomic and phylogenetic identification of the genus Bradyrhizobium using multilocus sequence analysis. BMC Genomics 16 (5), 1.

[8] Barcellos, F.G., Menna, P., da Silva Batista, J.S., Hungria, M. (2007) Evidence of horizontal transfer of symbiotic genes from a Bradyrhizobium japonicum inoculant strain to indigenous diazotrophs Sinorhizobium (Ensifer) fredii and Bradyrhizobium elkanii in a Brazilian Savannah soil. Appl. Environ. Microbiol. 73 (8), 2635-2643.

[9] Bell, L.W., Bennett, R.G., Ryan, M.H., Clarke, H. (2011) The potential of herbaceous native Australian legumes as grain crops: a review. Renew. Agric. Food Syst. 26 (1), 72-91.

[10] Beringer,J.E. (1974) Rfactor transfer in Rhizobium leguminosarum. Microbiology 84 (1), 188-198.

[11] Boiero, L., Perrig, D., Masciarelli, O., Penna, C., Cassan, F., Luna, V. (2007) Phytohormone production by three strains of Bradyrhizobium japonicum and possible physiological and technological implications. Appl. Microbiol. Biotechnol. 74 (4), 874-880.

[12] Coradin, L., Siminski, A., Reis, A. 2011 Espécies Nativas da Flora Brasileira de Valor Econômico Atual ou Potencial, Brasília Ministério Do Meio Ambient.

[13] De Almeida Ribeiro, P.R., dos Santos, J.V., da Costa, E.M., Lebbe, L., Assis, E.S., Louzada, M.O., Guimarães, A.A., Willems, A., de Souza Moreira, F.M. (2015)Symbiotic efficiency and genetic diversity of soybean bradyrhizobia in Brazilian soils. Agric. Ecosyst. Environ. 212, 85-93.

[14] Di Rienzo, J.A., Casanoves, F., Balzarini, M.G., Gonzalez, L., Tablada, M., Robledo, C.W. 2008 InfoStat, versión 2008, Grupo InfoStat, FCA, Universidad Nacional de Córdoba, Córdoba, Argentina.

[15] Delamuta, J.R.M., Gomes, D.F., Ribeiro, R.A., Chueire, L.M.O., Souza, R.C., Almeida, L.G.P., Vasconcelos, A.T.R., Hungria, M. (2015) Genome sequence of Bradyrhizobium tropiciagri strain CNPSo 1112T, isolated from a root nodule of Neonotonia wightii. Genome Announc. 3 (6), e01482-15.

[16] Del Papa, M.F., Pistorio, M., Draghi, W.O., Lozano, M.J., Giusti, M.A., Medina, C., van Dillewijn, P., Martínez-Abarca, F., Flores, B.M., Ruiz-Sainz, J.E., Megías, M., Pühler, A., Niehaus, K., Toro, N., Lagares, A. (2007) Identification and characterization of a nodH ortholog from the alfalfa-nodulating Or191-like rhizobia. Mol. Plant Microbe Interact. 20 (2), 138-145, http://dx.doi.org/10.1094/MPMI20-2-0138.

[17] Elliott, G.N., Chou, J., Chen, W., Bloemberg, G.V., Bontemps, C., MartínezRomero, E., Velázquez, E., Young, J.P.W., Sprent, J.I., James, E.K. (2009) Burkholderia spp. are the most competitive symbionts of Mimosa, particularly under N-limited conditions. Environ. Microbiol. 11 (4), 762-778.

[18] Ferreira, L., Sánchez-Juanes, F., García-Fraile, P., Rivas, R., Mateos, P.F., MartínezMolina, E., González-Buitrago, J.M., Velázquez, E. (2011) MALDI-TOF mass spectrometry is a fast and reliable platform for identification and ecological studies of species from family Rhizobiaceae. PLoS One 6 (5), e20223.

[19] Fornasero, L.V., Del Papa, M.F., López, J.L., Albicoro, F.J., Zabala, J.M., Toniutti, M.A., Pensiero, J.F., Lagares, A. (2014) Phenotypic, molecular and symbiotic characterization of the rhizobial symbionts of Desmanthus paspalaceus (Lindm.) Burkart that grow in the province of Santa Fe, Argentina. PLoS One 9 (8), e104636.

[20] Granada, C.E., Strochein, M., Vargas, L.K., Bruxel, M., de Sá, E.L.S., Passaglia, L.M.P. (2014) Genetic diversity and symbiotic compatibility among rhizobial strains and Desmodium incanum and Lotus spp. plants. Genet. Mol. Biol. 37 (2), 396-405.

[21] Group, L.P.W. (2013) Legume phylogeny and classification in the 21st century: progress, prospects and lessons for other species-rich clades. Taxon 62 (2), 217-248.

[22] Gu, J., Wang, E.T., Chen, W.X. (2007) Genetic diversity of rhizobia associated with Desmodium species grown in China. Lett. Appl. Microbiol. 44 (3), 286-292.

[23] Guimarães, A.A., Jaramillo, P.M.D., Nóbrega, R.S.A., Florentino, L.A., Silva, K.B., de Souza Moreira, F.M. (2012) Genetic and symbiotic diversity of nitrogenfixing bacteria isolated from agricultural soils in the western Amazon by using cowpea as the trap plant. Appl. Environ. Microbiol. 78 (18), 6726-6733.

[24] Heider, B., Fischer, E., Berndl, T., Schultze-Kraft, R. (2009) Genetic relationships among accessions of four species of Desmodium and allied genera (Dendrolobium triangulare, Desmodium gangeticum, Desmodium heterocarpon, and Tadehagi triquetrum). Trop. Conserv. Sci. 2 (1), 52-69.

[25] Jaiswal, S.K., Anand, A., Dhar, B., Vaishampayan, A. (2012) Genotypic characterization of phage-typed indigenous soybean bradyrhizobia and their host range symbiotic effectiveness. Microb. Ecol. 63 (1), 116-126.

[26] Jensen, H.L. (1942) Nitrogen fixation in leguminous plants. I. General characters of root nodule bacteria isolated from species of Medicago and Trifolium in Australia. Proc. Linn. Soc. NSW 66, 98-108.

[27] Jia, R.Z., Zhang, R.J., Wei, Q., Chen, W.F., Cho, I.K., Chen, W.X., Li, Q.X. (2015) Identification and classification of rhizobia by matrix-assisted laser desorption/ionization time-of-flight mass spectrometry. J. Proteom. Bioinform. 8, 98.

[28] Kitamura, R.S.A., Maranho, L.T. (2016) Phytoremediation of petroleum hydrocarbons-contaminated soil using Desmodium incanum DC., Fabaceae. Rev. Latinoam. Biotecnol. Amb. Algal 7 (1), 1-15.

[29] Kumar, S., Stecher, G., Tamura, K. (2016) MEGA7: molecular evolutionary genetics analysis version 7.0 for bigger datasets. Mol. Biol. Evol. 33 (7), 1870-4.

[30] Laguerre, G., Nour, S.M., Macheret, V., Sanjuan, J., Drouin, P., Amarger, N. (2001) Classification of rhizobia based on nodC and nifH gene analysis reveals a close phylogenetic relationship among Phaseolus vulgaris symbionts. Microbiology 147 (4), 981-993.

[31] Li, Q.Q., Wang, E.T., Chang, Y.L., Zhang, Y.Z., Zhang, Y.M., Sui, X.H., Chen, W.F., Chen, W.X. (2011) Ensifer sojae sp. nov., isolated from root nodules of Glycine max grown in saline-alkaline soils. Int. J. Syst. Evol. Microbiol. 61 (8), 1981-1988.

[32] Martinez-Romero, E. (2003) Diversity of Rhizobium-Phaseolus vulgaris symbiosis: overview and perspectives. Plant Soil 252 (1), 11-23.

[33] McInnes, A., Thies, J.E., Abbott, L.K., Howieson, J.G. (2004) Structure and diversity among rhizobial strains, populations and communities-a review. Soil Biol. Biochem. 36 (8), 1295-1308.

[34] Menna, P., Barcellos, F.G., Hungria, M. (2009) Phylogeny and taxonomy of a diverse collection of Bradyrhizobium strains based on multilocus sequence analysis of the 16S rRNA gene, ITS region and $\ln I I$, recA, atpD and dnaK genes. Int. J. Syst. Evol. Microbiol. 59 (12), 2934-2950.

[35] Mergaert, P., Van Montagu, M., Holsters, M. (1997) Molecular mechanisms of Nod factor diversity. Mol. Microbiol. 25 (5), 811-817.

[36] Mwangi, D.M., Wambugu, C. (2003) Adoption of forage legumes: the case of Desmodium intortum and Calliandra calothyrsus in central Kenya. Trop. Grassl. 37 (4), 227-238.

[37] Overbeck, G.E., Müller, S.C., Fidelis, A., Pfadenhauer, J., Pillar, V.D., Blanco, C.C., Boldrini, I.I., Both, R., Forneck, E.D. (2007) Brazil's neglected biome: the South Brazilian Campos. Perspect. Plant Ecol. Evol. Syst. 9 (2), 101-116.

[38] Parker, M.A. (1999) Relationships of bradyrhizobia from the legumes Apios americana and Desmodium glutinosum. Appl. Environ. Microbiol. 65 (11), 4914-4920.

[39] Peng, G.X., Tan, Z.Y., Wang, E.T., Reinhold-Hurek, B., Chen, W.F., Chen, W.X. (2002) Identification of isolates from soybean nodules in Xinjiang Region as Sinorhizobium xinjiangense and genetic differentiation of S. xinjiangense from Sinorhizobium fred. Int. J. Syst. Evol. Microbiol. 52 (2), 457-462.

[40] Rogel, M.A., Ormeno-Orrillo, E., Romero, E.M. (2011) Symbiovars in rhizobia reflect bacterial adaptation to legumes. Syst. Appl. Microbiol. 34 (2), 96-104.

[41] Sambrook, J., Fritsch, E.F., Maniatis, T. 1989 Molecular cloning, vol. 2, Cold Spring Harbor Laboratory Press, New York.

[42] Sánchez-Juanes, F., Ferreira, L., de la Vega, P.A., Valverde, A., Barrios, M.L., Rivas, R., Mateos, P.F., Martínez-Molina, E., González-Buitrago, J.M., Trujillo, M.E. (2013) MALDI-TOF mass spectrometry as a tool for differentiation of Bradyrhizobium species: application to the identification of Lupinus nodulating strains. Syst. Appl. Microbiol. 36 (8), 565-571.

[43] Schlueter, P.M., Harris, S.A. (2006) Analysis of multilocus fingerprinting data sets containing missing data. Mol. Ecol. Notes 6 (2), 569-572.

[44] Sinsuwongwat, S., Nuntagij, A., Shutsrirung, A., Nomura, M., Tajima, S. (2002) Characterization of local rhizobia in Thailand and distribution of malic enzymes. Soil Sci. Plant Nutr. 48 (5), 719-727.

[45] Tang, J., Bromfield, E.S.P., Rodrigue, N., Cloutier, S., Tambong, J.T. (2012) Microevolution of symbiotic Bradyrhizobium populations associated with soybeans in east North America. Ecol. Evol. 2 (12), 2943-2961.

[46] Tarré, R., Macedo, R., Cantarutti, R.B., De Rezende, C.P., Pereira, J.M., Ferreira, E., Alves, B.J.R., Urquiaga, S., Boddey, R.M. (2001) The effect of the presence of a forage legume on nitrogen and carbon levels in soils under Brachiaria pastures in the Atlantic forest region of the South of Bahia, Brazil. Plant Soil 234 (1), $15-26$.

[47] Thompson, J.D., Higgins, D.G., Gibson, T.J. (1994) CLUSTAL W: improving the sensitivity of progressive multiple sequence alignment through sequence weighting, position-specific gap penalties and weight matrix choice. Nucleic Acids Res. 22 (22), 4673-4680.

[48] Tiemann, T.T., Franco, L.H., Peters, M., Frossard, E., Kreuzer, M., Lascano, C.E., Hess, H.-D. (2009) Effect of season, soil type and fertilizer on the biomass production and chemical composition of five tropical shrub legumes with forage potential. Grass Forage Sci. 64 (3), 255-265.

[49] Vanni, R.O. (2001) El género Desmodium (Leguminosae, Desmodieae) en Argentina. Darwiniana, 255-285.

[50] Versalovic, J., Koeuth, T., Lupski, R. (1991) Distribution of repetitive DNA sequences in eubacteria and application to finerpriting of bacterial enomes. Nucleic Acids Res. 19 (24), 6823-6831.

[51] Vincent, J.M. 1970 A manual for the practical study of the root-nodule bacteria. In: International Biological Programme, Blackwell Scientific, Oxford.

[52] Vinuesa, P., Silva, C., Werner, D., Martínez-Romero, E. (2005) Population genetics and phylogenetic inference in bacterial molecular systematics: the roles of migration and recombination in Bradyrhizobium species cohesion and delineation. Mol. Phylogenet. Evol. 34 (1), 29-54.

[53] Wang, H., Man, C.X., Wang, E.T., Chen, W.X. (2009) Diversity of rhizobia and interactions among the host legumes and rhizobial genotypes in an agricultural-forestry ecosystem. Plant Soil 314 (1-2), 169-182.

[54] Wang, J.Y., Wang, R., Zhang, Y.M., Liu, H.C., Chen, W.F., Wang, E.T., Sui, X.H., Chen, W.X. (2013) Bradyrhizobium daqingense sp. nov., isolated from soybean nodules. Int. J. Syst. Evol. Microbiol. 63 (2), 616-624.

[55] Weidner, S., Arnold, W., Puhler, A. (1996) Diversity of uncultured microorganisms associated with the seagrass Halophila stipulacea estimated by restriction fragment length polymorphism analysis of PCR-amplified 16S rRNA genes. Appl. Environ. Microbiol. 62 (3), 766-771.

[56] Xu, K.W., Zou, L., Penttinen, P., Zeng, X., Liu, M., Zhao, K., Chen, C., Chen, Y.X. Zhang, X. (2016) Diversity and phylogeny of rhizobia associated with Desmodium spp. in Panxi, Sichuan, China. Syst. Appl. Microbiol. 39 (1), 33-40. 
[57] Xu, L.M., Ge, C., Cui, Z., Li, J., Fan, H. (1995) Bradyrhizobium liaoningense sp. nov., isolated from the root nodules of soybeans. Int. J. Syst. Evol. Microbiol. 45 (4), 706-711.

[58] Zhang, Y.M., Li, Y., Chen, W.F., Wang, E.T, Tian, C.F., Li, O.O, Zhang, Y.Z., Sui, X.H., Chen, W.X. (2011) Biodiversity and biogeography of rhizobia associated with soybean plants grown in the North China Plain. Appl. Environ. Microbiol. 77 (18), 6331-6342.
[59] Ziegler, D., Pothier, J.F., Ardley, J., Fossou, R.K., Pflüger, V., De Meyer, S., Vogel, G., Tonolla, M., Howieson, J., Reeve, W. (2015) Ribosomal protein biomarkers provide root nodule bacterial identification by MALDI-TOF MS. Appl. Microbiol. Biotechnol. 99 (13), 5547-5562. 